\title{
From Fuzzy Exploration to Transparent Advice: Insights into Mobile Advisory Services
}

\author{
Comes, Tino ; Schwabe, Gerhard
}

\begin{abstract}
Mobile advisory services are characterized by location-dependent and spatial distributed information, unknown environments and limited tool support. These aspects complicate mobile advisory services to the point that the delivered service appears rather fuzzy than transparent. To tackle that problem, we examine the practical field of home security advice and present an initial design solution. The system called "SmartProtector" adapts existing knowhow from the stationary advisory context and complements it with findings from a field analysis. Evaluation shows that we have been successful in reaching our objective of increasing transparency in home security advisory situations leading to more comprehension on the clients' side. In addition to the practical innovation, we contribute generic requirements to the discussion of transparency in service science by expanding the advisory service scope to the mobile dimension.
\end{abstract}

DOI: https://doi.org/10.1109/HICSS.2016.159

Posted at the Zurich Open Repository and Archive, University of Zurich

ZORA URL: https://doi.org/10.5167/uzh-125691

Conference or Workshop Item

Originally published at:

Comes, Tino; Schwabe, Gerhard (2016). From Fuzzy Exploration to Transparent Advice: Insights into Mobile Advisory Services. In: Hawaii International Conference on System Sciences, Kauai, Hawaii, 5 January 2016 - 8 January 2016, IEEE.

DOI: https://doi.org/10.1109/HICSS.2016.159 


\section{From Fuzzy Exploration to Transparent Advice: Insights into Mobile Advisory Services}

\author{
Tino Comes \\ University of Zurich \\ comes@ifi.uzh.ch
}

\author{
Gerhard Schwabe \\ University of Zurich \\ schwabe@ifi.uzh.ch
}

\begin{abstract}
Mobile advisory services are characterized by location-dependent and spatial distributed information, unknown environments and limited tool support. These aspects complicate mobile advisory services to the point that the delivered service appears rather fuzzy than transparent. To tackle that problem, we examine the practical field of home security advice and present an initial design solution. The system called "SmartProtector" adapts existing knowhow from the stationary advisory context and complements it with findings from a field analysis. Evaluation shows that we have been successful in reaching our objective of increasing transparency in home security advisory situations leading to more comprehension on the clients' side. In addition to the practical innovation, we contribute generic requirements to the discussion of transparency in service science by expanding the advisory service scope to the mobile dimension.
\end{abstract}

\section{Introduction}

Stationary advisory services (e.g., financial service encounter) have struggled with transparency problems over many years, until IT-support devised possible solutions [21]. However, mobile advisors (i.e. advisors who are on the move during advice giving) cannot benefit from the existing solutions as they are designed for fixed locations. We want to close this gap by providing insights into the phenomenon of transparency in mobile advisory situations as well as presenting an initial design solution.

In our study, we have examined a service in which providers and clients meet each other face-to-face. This interaction is well-known as the service encounter [7, 21]. During this encounter service provider (e.g., advisors) and clients (e.g., advice seekers) interact directly so that they are involved in their mutual activities and are able to influence each other [7]. Prahalad and Ramaswamy [24] consider this interaction between the actors as the locus of value co-creation. For this reason, the quality of interaction is essential for value cocreation [7]. From the perspective of service-dominant logic, value co-creation is an interaction process in which the clients participate as co-producers and the providers act as co-creators [7, 34] (for example, during advisory services advisors suggest solutions and clients adapt them to their needs). In order to enable the clients to be co-producers and the providers to be co-creators, the joint process must conform to specific interaction needs. An appropriate model that addresses these needs is the DART model [24]. This model determines the interaction elements that are essential for successful value co-creation. These are dialog, access, transparency and the understanding of riskbenefits. We focus in this study on transparency.

Advisory service for home security illustrates well which characteristics of advice giving on the move hamper the transfer of stationary solutions and simultaneously increase the negative impact on transparency. We could identify inherent characteristics which lead to non-transparent work practices, lack of client participation during the exploration and the subsequent inability of the client to make informed decisions [15].

Home security advisors are only one category of many mobile employees in a growing mobile business today (cf. [9]). However, they represent a group of mobile people working in collaborative tasks while on the move (e.g., energy consultants, architects) and especially can benefit from mobile collaboration support [11] or even rely on it for carrying out their tasks [10]. While there has been some research on transparency in stationary settings, e.g., financial service encounter $[21,22]$, travel counseling [29] or government advisory services [17], transparent advice giving has not yet been addressed in mobile settings. In practice, the lack of transparency inhibits clients to understand what the advisors want to communicate. This limitation results in a low implementation rate of advisory outcomes. As official providers of home security advice reported, they expect only less than $20 \%$ of given advice to be implemented [30]. Therefore, we aim on increasing the transparency in such mobile advisory situations. Thus, we want to answer to the following research question:

How can we improve mobile advisory services by enhancing transparency? 
We will present the answer to this research question as a set of generic requirements and a prototypical instantiation of a solution. The following section defines the role of transparency in advisory services, gives an insight into existing solutions in the field of stationary advisory support and builds up a bridge to mobile collaboration support. Subsequently, we explain our design science research approach that provides a structured research guideline. The consecutive section presents mobile advisory service in general and then describes the practical home security advisory service in more detail. In the fifth section we derive generic requirements which contribute to the existing design knowledge. The sixth section demonstrates our design solution in form of an IT-artifact, which will be evaluated in the seventh section. We end with a discussion and conclusion in which we reflect on the results and outline what we have learned and further need to be learned.

\section{Related Work}

Research on service science moves from general value co-creation to co-creation experience [24]. Clients of travel advisory, for example, would like to be involved in the travel planning experience. Therefore, clients and service providers need to enter an active dialog [24]. This dialog requires input from clients (e.g., needs, client context) and service provider (e.g., offer explanations) [21]. This conversation would be difficult if both sides have not the same transparency and access to the information [24].

Without sufficient transparency, clients consider advisory services as not trustworthy (cf. [21]), they participate less in the collaborative advisory process resulting in less individualized advisory outcomes (cf. $[28,21])$. Furthermore, the lack of transparency inhibits clients' cognitive information processing [5] and leaves them less convinced about the outcome [17]. With this in mind, we believe that the lack of transparency in general leads to a high client dissatisfaction [21] and results in low implementation abilities on the clients' side, which in its turn hampers a successful advisory completion.

Transparency is still a complex construct that has been discussed in various research fields like economics, $\mathrm{CSCW}$ [22] or value co-creation literature [24]. In general, it is used as a characterization for something that can easily be understood or seen through [3]. However, transparency advisory services can be described more specifically [22]. A more appropriate definition related to advice giving is found in the context of political science, in which "transparency refers to the accessibility of the processes involved in decision making in addition to the outcome and to information itself. Transparency also involves proactive dissemination to the consumer of this information, knowledge and access" ([19] in [21]). Mahoney and Webley [19] also distinguish between information transparency (access to information) and process transparency (access to process). Nussbaumer [21] adapted this definition to transparency in advisory services. For him information transparency includes "what information is relevant and why is it considered as relevant by the advisor." Process transparency, he defines as the "degree of the client being able to follow and comprehend the performed advisory activities" In consideration of this we have to look at both aspects (information and process transparency) in mobile advisory services.

Knowing about the consequences of the lack of transparency and how it occurs in advisory services, we want to look at existing solutions which provide transparency. Previous approaches within the stationary advisory research mainly suggest that an artifact can increase transparency. Nussbaumer et al [21] demonstrated over two design iterations how they had increased the transparency in financial advisory situations. They provided an interactive multi-touch table at which clients and advisors sat down and interacted with the software. They showed that a software design based on "casual" transparency is more effective than one based on "enforced" transparency. This means that advisors and clients dislike a fixed advisory process and disturbances in their small talk due to a strong presence of the IT-artifact. Furthermore, the research revealed that the relationship between important information items (e.g., risk preferences and investment strategy) should be visible in one screen.

In travel counseling research, Novak \& SchmidtRauch [20] aimed at reducing information asymmetries (transparency and information asymmetries are often used synonymously) with the help of shared visualizations. For this purpose, advisors virtually guided clients toward destinations in front of a large smartboard. The researchers noted that focus on the relationship between client and advisor is important and the solution should therefore be very easy to use. For example, without unnecessary control activities performed by advisors more attention can be paid to the clients. Both the travel solution and the banking solution were based on large screens. Yet, in mobile advisory settings we cannot use such fixed and large systems and have to search for alternative solutions.

In addition, visualized explanations are the key factor for successful advisory systems. This again is a challenge in a mobile setting. Seifert et al. [32] show that separating tasks may be a solution: An initial inquiry phase collects information and convergent 
tasks are being postponed until a stationary shared large display is available. However, it is unclear to what extent their results hold for mobile advice giving. They addressed decision making between equals and did not rely on location-specific information.

\section{Research Methodology}

We base our research methodology on Hevner's [13, 12] established IS Research Framework (ISRF). The framework describes a design science research methodology in three cycles called "relevance cycle", "design cycle" and "rigor cycle". We followed the steps of the Design Science Research Method (DSRM) proposed by Peffers [23]. The method consists of six steps: "Identify Problem \& Motivate", "Define Objectives of a Solution", "Design \& Development", "Demonstration", "Evaluation" and "Communication". In the following section we will describe our research method according to these six steps:

1) We started problem-centered by analyzing the environment as defined by Hevner's [13] ISRF relevance cycle. Using the Needs Driven Approach (cf. [31]) we collect data on goals, interaction, process support, and specific home security needs from two highly experienced advisors and four real clients in semi-structured interviews in 2012. This was complemented by targeted observations of three real advisory sessions providing home security advice. We revisited the problem analysis later in each of the evaluations and in a continuous discussion with advisors and their bosses.

2) In a second step we formulated design ideas in a form of initial mockups and storyboards (based on a HCI technique as defined in [18]). This was done by a creative causal analysis approach [6]. Further, we refined our ideas in focused design iterations with a group of all stakeholders. Our ideas have been inspired by the analyzed problems as well as concepts in the literature (described in section II). That enabled us to address the ISRF's rigor cycle and base our design solution on existing models and methods.

3) The further steps of DSRM ("Design \& Development", "Demonstration" and "Evaluation") correspond to the ISRF design cycle. We began transferring our design ideas into a testable prototype with the help of the Scenario Based Development Method of Rosson \& Carroll [25] using the findings of the problem analysis as well as the previously created design ideas. The prototype was designed and optimized in several iterative phases with focus groups. The groups included three researchers with expertise in the field of advisory service supporting information systems as well as two advisors and service managers from a police department which provides home security advice. Furthermore, after each test the software was redesigned based on the test feedback.

4) On a yearly basis there was an evaluation in a field test that started a further design iteration. The first test was conducted in 2013 in Switzerland with two advisors and twelve clients. The second test took part in summer 2014 in Switzerland with six advisors and twelve clients. In spring 2015 we evaluated our design in Germany with ten advisors and twenty clients. All advisors in each evaluations were real home security advisors. This paper reports on the most recent test. It was triggered by the interest of police headquarters of two German states. We chose a within-subject design and thus we can report on forty advisory sessions (twenty supported, twenty unsupported by our tool). We tested with real home security advisors from local police departments and used eight real show houses from two model parks. So we could ensure that the advisors experienced a new environment in each advisory session. The test clients represented a typical cross-section of clients and were each assigned to a single home security advisor. In the first session advisors went with their client through an app. 30minute advisory process. After that they moved to another house and went through an advisory session again, but switched from either conventional support to the prototype-supported mode or vice versa. In this way each test client experienced both, the traditional and the IT-supported advisory service in a withinsubject design [33]. On one day each home security advisors completed four advisory sessions. They started their session supported by the prototype in the morning and switched afterwards. In the afternoon they started with the conventional service and switched to the IT-supported one. All sessions were accompanied by researchers and recorded on video. We collected data using questionnaires and interviews and videotaped the sessions. Thereby, the camera focused mainly on facial expressions and gestures of the client to observe differences in reactions. Later we will describe the data analysis in detail together with the results.

5) After the last evaluation we derived our requirements from the tested design ideas. These design ideas are based on established generic requirements from the studied service literature (e.g., "casual" transparency concept [21]) and complemented by mobile needs. As it is typical for Design Science Research it is difficult to prove that they are useful or even "true" [16]. Nevertheless, the detailed problem analysis and the successful evaluation support the validity of the proposed requirements. 


\section{Mobile Advisory Services \& the Case of Home Security Advice}

Mobile advisory services differ from stationary advisory services in certain aspects, which hamper a transparent service. Three characteristics of mobile advisory services are the main cause. 1) In mobile advisory service encounters relevant information is location-dependent and spatially distributed. It is tied to a certain physical location and cannot easily be processed by the advice seekers. In these cases, the advisors must explore, collect and process the information locally. 2) Mobile advisory services are particular heterogeneous. Each advisory client has his own individual physical environment. This means that the advisors face an unknown environment for each new client. In order to find the advisory relevant information advisors need to use heuristic search algorithms based on their experiences from previous explorations. Thus, the actual advisory process (sequence of advice activities) is always formed ad-hoc (during the actual advisory process). Therefore the process cannot be communicated in advance to the client. 3) While both advisors and advice seekers are on the move during the exploration, exchange of information and communication of process, activities are limited. The mobility and flexibility of the actors make it difficult to simultaneously access a shared information space. Tools that require large shared displays or extensive keyboard input are not literally appropriate for transport and use while on the move.

All three characteristics mentioned previously can be observed in this service and are described in a problem scenario after below.

"Home Sweet Home" is well known for each of us. We feel uncomfortable when our property is threatened. This can happen, for example, due to a burglary. Preventive home security advice can provide help in such situations. Advisors who are experts in home security visit you at home and analyze your property regarding weak points. This advisory service consists of three general phases (based on [9]). The first phase, called exploration phase, deals with the search and assessment of all weak points. In the subsequent conception phase security recommendations to eliminate the detected weak points are elaborated. In the last phase the advice seeker is responsible for the implementation of the given recommendations.

The following problem scenario (cf. [25]) condenses the results of all observed home security advisory sessions since 2012. It includes real problem situations and is validated by real clients and advisors. The scenario illustrates how transparency problems occur in the home security advisory service.
Sophia is a young lady and recently moved because of her new job. She had heard from the media about a series of burglaries close to her home. Promptly she feels scared. In the Internet she finds an advisory service offered by the local police. Sophia herself has never received such a service at home. Therefore she has no idea what awaits her. The expert Michael answers to her request and confirms an appointment at the following week. Michael arrives as promised and starts with the exploration of Sophia's home right after a brief greeting. He immediately notices the garden, which is frequently the entry for burglars. Michael asks Sophia to follow him to the windows facing the garden. He knocks two-three times against one glass and states that this window is a weak point. This is difficult to understand for Sophia because all these windows are quite new. She dismisses her doubts for the moment, because Michael has already confronted her with a question about the next window. He wants to know if she opens it from time to time or always keeps it closed. Sophia says that she does not need to open it. Thereupon Michael recommends locking the window permanently. Sophia is uncertain about how this would look like. She has never seen a permanently locked window. Together they continue the exploration. Yet, Sophia has difficulties in following the activities of the advisor. She feels still unclear about his and her role in the process as well as what has triggered his activities. For example, Sophia does not know why Michael has asked her about her behavior exactly at the second window but not at other windows. Sophia asks herself whether this means that the first window is relevant or not. Moreover, Sophia does not detect a pattern in Michael's procedure. Because Michael is still busy with the exploration, she does not want to disturb him and is cautious about asking questions. After Michael is convinced that he has found all weak points he comes up with a conclusion. He thinks that an alarm system meets her needs. He noted this briefly on a sheet of paper, put in a brochure about home security and passes it to her. Sophia is surprised by what this solution means for the previously given recommendations, like the permanently locked window. Furthermore, Sophia does not understand exactly in what way the alarm system is related to each single weak point they have discovered. Finally, she remains undecided in her intention to install the alarm system or follow the other recommendations because she does not believe that the alarm system meets her original need.

The previous and highly specific story about Michael advising Sophia highlights transparency problems faced by clients of conventional mobile advisory services. The advice seekers, usually never confronted with a mobile advisory process before, are 
unable to interpret advisor's activities and fail in processing given technical information. From the clients' perspective the outcome of the advisory service could change with each discovered location (e.g., previous recommendations could become obsolete due to cross-locational solutions). This seems to be arbitrarily to the advice seekers.

\section{Generic Requirements for Mobile Advisory Services}

We argue that the negative effects from the lack of transparency result in a low service quality in mobile advisory services. This problem originates from the characteristics of mobile advisory situations and can be assigned to the lack in information transparency and process transparency as described in the 2nd section. Based on this, we are able to derive six generic requirements which will support transparency in both dimensions. We present each requirement as follows: first we enumerate the concrete problem of the clients followed by one or more descriptions of what exactly is problematic. Each description is prefaced with an "example" quoted from the problem scenario (see section IV) and concludes with the associated requirement.

\subsection{Information Transparency}

As explained in section II, any information which is relevant for the mobile advisory process needs to be accessible so clients can understand and evaluate this information. Otherwise, clients may fail in comprehending their status-quo situation and given recommendation or misinterpret the relation between these two advisory aspects.

1) Clients fail to comprehend their status quo situation:

"Sophia asks herself whether this means that the first window is relevant or not."

During the exploration phase, advisors can only partially evaluate, whether and to what extent discovered locations are relevant to the overall status quo situation. This is not a problem for the advisors, because they are able to use their experience to decide what information is important to remember. However, clients are unable to access the preliminary list of information. Accordingly, clients do not know what status quo information is relevant (cf. [22]). For example, a client comments in an interview: "Actually, if we need something [solutions] or not is not clear".
GR1 "Problem-Relevance-Transparency": During exploration, provide clients with clues to which observations indicate a new problem.

"This is difficult to understand for Sophia because all these windows are quite new."

Advisors, in the role of an expert, often fail to establish a common ground to bridge the gap of expertise [14] to their clients. As clients do not have the same level of knowledge (expert-lay-paradigm) they cannot process technical information as for example the resisting power of glass. Accordingly, clients do not understand why the given status quo is problematic (cf. [22]). Therefore, we formulate the 2nd generic requirement as the following.

GR2 "Problem-Rationale-Transparency": At each location, give clients information on why the status quo is problematic.

2) Clients fail to comprehend their received recommendations:

"Sophia is surprised by what this solution means for the previously given recommendations"

In general, advisors have a set of different recommendations in mind to choose from. During the service encounter they often mention various possible solutions accumulating a temporary list of potential solutions. However, which of these are relevant to the clients' needs and overall solution remains unclear. Jungermann [15] attributes this effect to advisory situations in which clients are rather confronted with predefined solutions than integrated in the solution finding process. Accordingly, clients do not know what recommendation is relevant (cf. [22]). Addressing this we formulate the next requirement:

GR3 "Solution-Relevance-Transparency: With each new introduced solution proposal, visualize the client what this means for the overall solution.

"Sophia is uncertain about how this looks like. She has never seen a permanently locked window."

It is even more difficult to explain a possible future state than the current status-quo situation. While discovering weak points, advisors cannot reference possible solutions because they are not on site. For example, a test client wanted to know how an alarm system would work in her house. The advisor could not show on site how it would be installed and work. Accordingly, clients do not know why the given 
solution information is appropriate (cf. [22]). We address this challenge with the following generic requirement.

GR4 "Solution-Rationale-Transparency": At each location, give clients information on why the proposed solution will solve the problem.

3) Misinterpretations of the relation between the status quo situation and recommendations:

"Sophia does not understand exactly in what way the alarm system is related to each single weak point they have discovered."

During the exploration phase the status quo situation has been established for the advisor and the client. The advisor has added various recommendations, which improve either the status quo at one single location or the overall situation. In the end of the advisory service encounter clients have difficulties to match the recommendations to the specific locations correctly. For example, a client stated: “(...) when we were in the basement, it was clear what and where I had to do. However, when we were sitting at the table, more things were discussed, but for me it was not clear how this was related to the problems in my basement". One requirement is that the client can easily assign the recommendations (e.g., locking system) to the discovered status quo (e.g., weak window) and the correct physical location (e.g., next to the main entrance).

GR5 "Decision Information Transparency": Visualize the link between observed problems and recommended solution.

\subsection{Process Transparency}

Collaboration requires coordination of the different activities. Coordination in turn requires understanding of the actors' activities. Thus, only when the clients understand what the advisors are currently involved in and how this relates to the prior activities, they can contribute constructively. The issue of the process transparency appears on two levels: when the advisor explores a single object and at the level of the whole advisory session:

"Moreover, Sophia does not detect a pattern in Michael's procedure. Because Michael is still busy with the exploration, she does not want do disturb him and is cautious about asking questions."

At each location the exploration process consists of four activities. Home security advisors identify the problem type, describe what the problem is, give explanations why this is a problem and keep the information for later decisions. The sequence and the occurrence of these activities often appear arbitrary. Clients, who have typically never experienced such a mobile advisory process, do not understand what has triggered an activity on-site and why it is performed. If any information concerning the location remains unclear, clients hesitate to interrupt advisors in their process hoping that the answer will be delivered later. But often advisors move to the next location before clients' questions have been integrated in the advisory process. However, the integration is crucial in advisory situations as claimed by Nussbaumer [21] and Schmidt-Rauch \& Nussbaumer [28].

GR6 "Process-Transparency": Provide the client with clues on the location and logical sequence of activities.

\section{Design Solution}

Using our requirements we developed the SmartProtector prototype to increase transparency in mobile advisory situations. The SmartProtector has a simple and clear structured interface on a tablet PC with an 11.6 inch display, which is being used by the advisors during the whole service encounter. Depending on the activity, it can serve as a shared information space between advisors and clients. For this reason the SmartProtector can switch between an inquiry and a discussion mode as described by Seifert et al. [32].
Fig.1: Using SmartProtector on-site

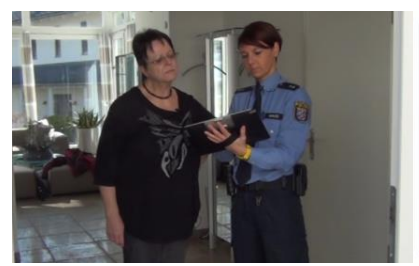

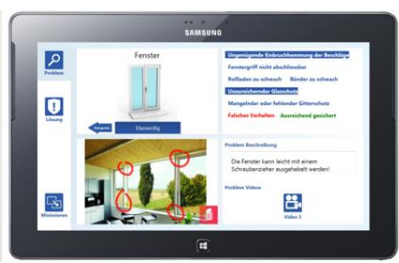

Fig.2: The problem space
Supported by the prototype, advisors record location-dependent information during the exploration phase. By taking photos of a problematic location (e.g., back door prone to burglary) they are able to pick up information-rich on-site impressions. They select the type of object from the list (e.g., door, window) and describe the underlying problem by touching keywords in a tag cloud. In doing so, advisors can choose from keywords to mark the existence of a weak point. The note-taking activities of the advisor (Fig.1) provide the client with an implicit clue on which observations are relevant and which not (GR1). 
The SmartProtector provides a database of suitable videos and pictures which can support advisors' explanations and allows clients to illustrate given information [cf. 17] during the mobile exploration phase. This multimedia information demonstrates why the observations are problematic or why recommended solutions are appropriate (GR2, GR4). This explanation happens either at the concrete problem location (Fig.1) or at the table in the subsequent phase (Fig. 4). Moreover, advisors can highlight certain details (Fig.2) by drawing on captured photos with their fingers (e.g., circle around weak points, arrows pointing the possible way burglar would take). This way they visualize previously hidden information for the clients.

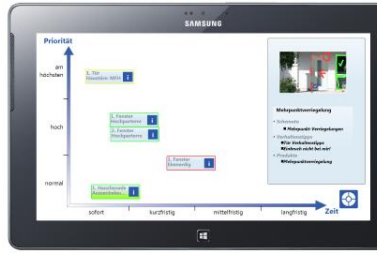

Fig.3: The priority screen

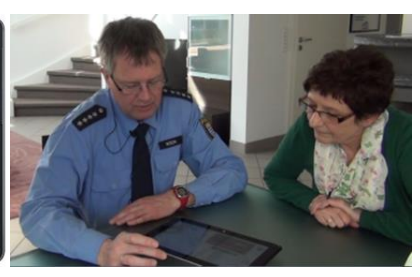

Fig.4: Collaboration with the SmartProtector
Each input of advisory relevant information is saved in a specific location notecard. This notecard represents a single location which can easily be identified by the captured photo. The notecard is divided into two tabs. One is called problem space and includes all information about the status quo situation of the associated location (Fig. 2). The other tab provides access to the library of possible solutions, which the advisors use to explain and visualize the solution to the client (GR2). We call this the solution space. Thus, the notecard establishes a link between status quo information and given recommendations (GR5).

The SmartProtector encourages advisors to follow the previously described on-location activities in a consistent order as well as an overall process in which the exploration is imbedded efficiently. We implemented four sub spaces in the problem space (Fig. 2) representing the activities at each location. Following these steps, advisors first select the problem type, secondly describe the problem, thirdly show problem type dependent explanations and finally integrate photos of the location. The repetition of always the same activities quickly makes them transparent to the client (GR6). The collection of all notecards allows advisors and clients to recapitulate the whole exploration phase in the subsequent planning phase at the clients' kitchen desk (Fig 4). Moreover, we implemented an overall process, in which the prototype ensures that the advisors and clients jointly discuss again clients' needs and all discovered locations while arranging each problem in a diagram of time and priority (Fig. 3).

The following activity scenario (cf. [25]) demonstrates how the implemented requirements act and improve the client situation in mobile advisory service encounters:

Again Michael is on-site at Natalie's home in his job as a home security advisor. He uses the tablet PC system SmartProtector to guide Natalie through the whole advisory session. At first he examines the entrance door. There he shows her a video on how a burglar breaks such a door. Immediately Natalie recognizes the weakness of her door and understands why she should replace it. After that they look together at all windows on the backside of her home. Michael takes a note that they are as sufficiently secured so that Natalie does not need to consider them later. But Natalie notices that Michael does not take a photo of all windows. She stops him before he goes on and asks why. Michael tells her that the windows are identical and therefore can be considered equal. Next Michael detects the weak back door. Michael recommends Natalie to upgrade it with a multipoint lock. He uses the SmartProtector to show her how such a lock system works and looks like. Michael has finished his exploration and asks Natalie to sit down with him at a table. Now she gets an overview over all discovered locations provided by the SmartProtector. By opening each individual location folder she sees the problem description and related recommendations. Michael and Natalie jointly repeat all explored locations, whereby Michael maps all given recommendations to a diagram ranking his proposed priorities and including an implementation schedule. Natalie realized that the diagram proposes to replace the expensive entrance door until the end of this month. This is not possible for her because she does not have the required financial resources. Accordingly, Michael revises the plan and gives her a few tips for the transition period. In this way, Natalie actively participates in the creation of her individual security solution.

\section{Evaluation}

Value creation is a primary research objective of design science (cf. [1, 13]). We evaluated this objective by implementing a more comprehensible advisory service and measured client satisfaction.

The evaluation compares the traditional approach using brochures and notes on a sheet of paper with our IT-supported transparent guiding approach. Test clients and advisors were instructed to fill out a questionnaire after each test session and gave us feedback in an interview at the end of their test participation. 
We measured to which extent the advice seekers can follow the mobile advisory process and understand the received information [22]. We focused on the mobile activities by asking our test clients on how well they have understood their status quo situation. This knowledge is generated during the mobile exploration phase. Moreover, we have measured how well the test clients have understood the received recommendations. This implies that the clients have built up a link between the information collected and the resulting recommendations.

The overall success of the mobile advisory service has been operationalized by asking the test clients if they feel able to implement the given recommendations (cf. [17]). Test clients should assess the extent to which they can implement the jointly developed security plan. The clients were presented with items for which they had to state their preference toward the conventional or the IT-supported service. An exemplary item is: Which of the experienced advisory services was more tailored to you? The scale, for this, had five levels ranging from: "conv++" = conventional was most tailored; "conv + " = conventional was slightly more tailored; "neutral" = there was no difference in the personalization between conventional and IT-supported service; "IT+" = IT-supported was slightly more tailored to "IT++" = IT-supported was most tailored.

Finally, we asked the test clients if in case of an advisory situation in their own homes they would choose the conventional or the IT-supported advisory service. Thereby we wanted to elaborate the test clients' intention to use the IT- supported service.

The results were collected from our test clients, nine of them were female and eleven were male, who had never received home security advice before. They had an average age of 53 the youngest being 19 and the oldest 81 years old. Ten of the participants live in their own house, six live in a flat and three of them only rent a single room.

\subsection{Results}

Using the SmartProtector participants could easier understand their status quo situation. Nine of twenty test clients (45\%) perceived their status quo situation more understandable in case of IT-supported sessions. Eight test clients (40\%) experienced no difference between both and the remaining three test clients (15\%) perceived conventional advice as more comprehensive regarding the status quo situation (Fig. 5).

During the test sessions the use of the SmartProtector enhanced clients' comprehensibility of received recommendations. In the evaluation, eleven test clients $(55 \%)$ indicate that they perceived the recommendations more comprehensive in the prototype supported advisory sessions. Seven participants $(35 \%)$ were indifferent towards both advisory versions and two (10\%) participants tended to better understand the given recommendation in conventional sessions (Fig. 6).

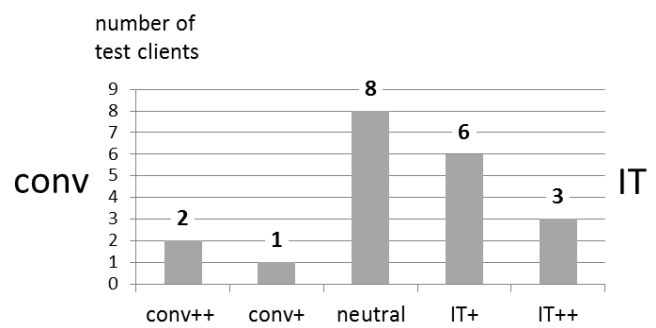

Fig.5: Perceived comprehensibility of status quo

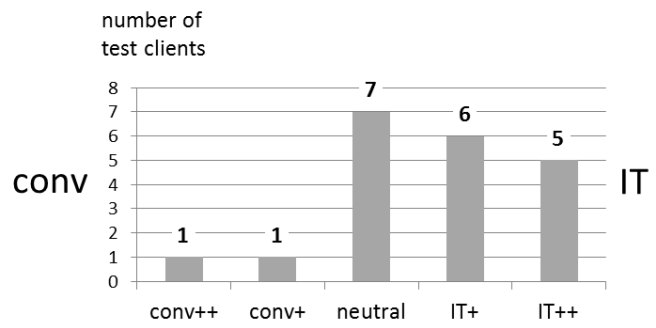

Fig.6: Perceived comprehensibility of received recommendations

Moreover, the IT-supported mobile advisory service provides a better preparation for the upcoming implementations and therefore more successfully empowers clients in their implementation skills than the conventional service (Fig. 7): of all participants, twelve $(60 \%)$ reported a higher perceived ability for an upcoming implementation of the recommendations compared to two $(10 \%)$ participants who felt more empowered in conventional sessions. Six participants $(30 \%)$ could not perceive any differences between the tested advisory versions.

In overall, the participants preferred the SmartProtector based home security advisory service (Fig. 8). Sixteen of the participants $(80 \%)$ stated that they would choose the prototype supported service if they have been advised at their real home. Two participants $(10 \%)$ did not answer this question and two other participants $(10 \%)$ would desire the conventional service for home security advice in their own home.

In addition to the results mentioned above, we can report a high interest from our field partners. The Zurich city police will transfer the SmartProtector into a software product. Two similar requests have reached us from German state police departments. 


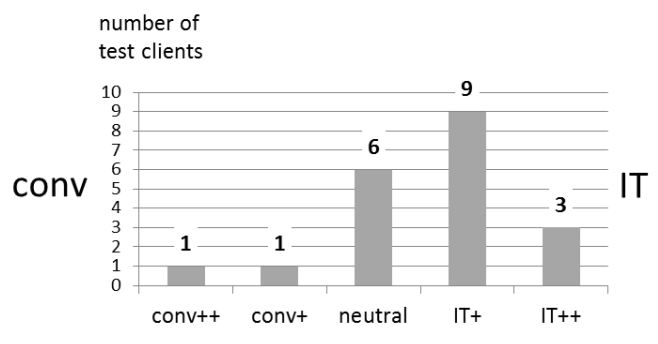

Fig.7: Perceived ability to implement the recommendations

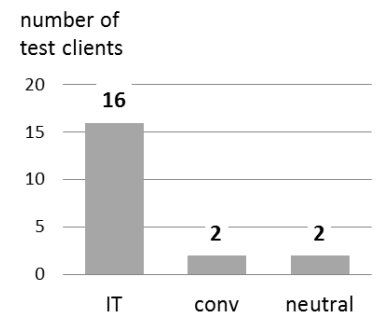

Fig.8: Preferred advisory service

\section{Discussion and Conclusion}

Support for mobile advice giving is still in its infancy. Relevant problems and solutions still need to be explored. The study shows how value co-creation processes are inhibited due to the limited interaction in mobile advisory settings (e.g., lack of transparency). We therefore support the proposition of Grönroos [7] that interaction is the key construct in providing services, which has been neglected in the literature. We propose that interaction in advisory services should be viewed as a highly situated variable, depending on where and how (mobile or stationary) the service takes place.

We furthermore contribute to a deeper understanding of the problem environment [13]. For this purpose, we reported from our field analysis where we have found the same distinction between information and process transparency as in stationary settings [22]. However, they occur differently in cases of mobile settings. The analysis shows that location-dependent information is not continuously present and crosslocation process steps are not connected to each other. Two special cases of information transparency occur: Is a problem or solution discussed really relevant? And why is an observed object a problem or why is a proposed measure a solution? Furthermore, the mobile process can be non-transparent, preventing interaction and value co-creation. With SmartProtector we offer a possible solution based on six generic requirements:
To improve transparency, the SmartProtector captures and presents location-dependent information (e.g., problem relevance or recommendation rationales). Either during the exploration or in the colocated planning session afterwards this information is presented to the client. This supports comprehension and clarifies misunderstandings on clients' side. In addition, we have succeeded in the implementation of the "casual-transparency" concept [22]. Instead of stipulating a restrictive process the SmartProtector design solution rather follows an informative guided approach [22]. The implemented toolboxes with suggested order of activities ensure an autonomous sequence which can be influenced by advisors and clients. This results in a high preference for the ITsupported advisory on clients' side.

Advisory services must clearly demonstrate the relevance of the advisory content, personalize the information supplied and structure it [17]. By taking photos of clients' problematic locations and marking those on the photo advisors emphasize the personalization. Furthermore, the visualized combination of photo, located problem and located solution as well as the suggested overall process provides a structure that facilitates clients to continue an independent implementation of the given recommendations (Fig. 7).

The insights from this study also contribute to the providers of mobile advisory services. They serve as a starting point to examine lacks in the effectivity of such services, some of which have been criticized, for example, by Frondel et al. [4] in relation to energy efficiency advice at home. Providers of home security advice generate their own value through the subsequent implementation of their given advice. We believe that the transparent advice approach leads to a higher rate of implementations in comparison to the conventional service. However, we were not able to evaluate this in our study, because our test clients were not the owners of the show houses and cannot implement there the given advice. A further limitation results from the nature of within-subject test designs. On the one hand, there is disadvantage because test clients could confuse the treatments (conventional, IT-supported) when they reflect on the test sessions [2]. On the other hand, we noted in previous interviews that test clients were not able to identify the benefit of the IT-support without comparison.

Finally, further research is needed to get a deeper understanding of the design and impact of mobile advisory services, e.g., How can we increase not only the ability but also the motivation of clients to implement the advice? Should we apply triggers such as E-Mails to remind them after three months? For this reason, we will continue to examine our rich data sets. 


\section{References}

[1] Benbasat, I. and R.W. Zmud, "The identity crisis within the IS discipline: Defining and communicating the discipline's core properties", MISQ, 2003, pp. 183-194.

[2] Charness, G., U. Gneezy, and M.A. Kuhn, "Experimental methods: Between-subject and within-subject design", 2012.

[3] Fellbaum, C., WordNet, Wiley Online Library, 1998.

[4] Frondel, M., P. Grösche, and C.M. Schmidt, "Energiesparen?", Energiewirtschaft, 32(2), 2008.

[5] Giesbrecht, T., T. Comes, and G. Schwabe, "Back in Sight, Back in Mind: Picture-Centric Support for Mobile Counseling Sessions", in Proceedings of CSCW. 2015.

[6] Gregor, S., O. Müller, and S. Seidel, "Reflection, Abstraction And Theorizing In Design And Development Research", in Proceedings of ECIS. 2013.

[7] Grönroos, C., "Value co-creation in service logic: A critical analysis", 2011.

[8] Habermann, K., "AVENTEON Mobile Business Assistant", Wirtschaftsinformatik, 47(1), 2005, pp. 55-62.

[9] Handler, G., Konzept zur Entwicklung integrierter Beratung, Wiesbaden, 2007.

[10] Hawkey, K., M. Kellar, D. Reilly, T. Whalen, and K.M. Inkpen, "The proximity factor: impact of distance on colocated collaboration", 2005.

[11] Herskovic, V., S.F. Ochoa, J.A. Pino, and A. Neyem, "General requirements to design mobile shared workspaces", in Proceedings of CSCWD. 2008.

[12] Hevner, A.R., "A three cycle view of design science research", Scandinavian journal of IS, 19(2), 2007, p. 4.

[13] Hevner, A.R., S.T. March, J. Park, and S. Ram, "Design science in information systems research". MISQ, 2004.

[14] Hinds, P.J. and J. Pfeffer, "Why organizations don't know what they know". 2003.

[15] Jungermann, H., "Advice giving and taking", in HICSS 32 - 32nd Annual Hawaii International Conference on System Sciences, Maui, HI, USA, 5-8 Jan. 1999.

[16] Kornwachs, K., Strukturen technologischen Wissens: Analytische Studien $\mathrm{zu}$ einer Wissenschaftstheorie der Technik, Berlin, 2012.

[17] Li, M. and S. Gregor, "IT empowerment or exclusion? The dilemma of online government advisory services". 2010.

[18] Maguire, M., "Methods to support human-centred design". 2001.
[19] Mahoney, M.S. and P. Webley, "The impact of transparency: A cross-national study", 2004.

[20] Novak, J. and S. Schmidt, "The Importance of Hedonic Stimulation in Collocated Collaboration with LargeDisplays", Proceedings of IFIP TC, 2009.

[21] Nussbaumer, P., Essays on transparent IT support for asymmetric client-advisor encounters, 2012.

[22] Nussbaumer, P., I.S. Matter, and G. Schwabe, "“Enforced" vs. "casual" transparency - Findings from ITsupported financial advisory encounters", 2012.

[23] Peffers, K., T. Tuunanen, M.A. Rothenberger, and S. Chatterjee, "A Design Science Research Methodology for Information Systems Research", 2007, pp. 45-77.

[24] Prahalad, C.K. and V. Ramaswamy, "Co-creation experiences: The next practice in value creation", Journal of Interactive Marketing, 18(3), 2004, pp. 5-14.

[25] Rosson, M.B. and J.M. Carroll, Usability engineering: Scenario-based development of human-computer interaction, 1st edn. Academic Press, San Fancisco, 2002.

[26] Sandström, S., B. Edvardsson, P. Kristensson, and P. Magnusson, "Value in use through service experience", 2008.

[27] Schmidt-Rauch, S., M. Fux, and G. Schwabe, "Tourist office counselling service". 2011.

[28] Schmidt-Rauch, S. and P. Nussbaumer, "Putting Value Co-Creation into Practice: A Case for Advisory Support", in Proceedings of ECIS. 2011: Helsinki.

[29] Schmidt-Rauch, S. and G. Schwabe, "From telesales to tele-advisory in travel agencies", TMIS, 2(3), 2011, pp. 17:1$17: 23$.

[30] Schwabe, G., R.O. Briggs, and T. Giesbrecht, "Advancing Collaboration Engineering: New ThinkLets for Dyadic Problem Solving and an Application for Mobile Advisory Services", 2016.

[31] Schwabe, G. and H. Krcmar, Der Needs Driven Approach-Eine Methode zur bedarfsgerechten Gestaltung von Telekooperation, Springer, 1996.

[32] Seifert, J., A. Simeone, D. Schmidt, P. Holleis, C. Reinartz, M. Wagner, H. Gellersen, and E. Rukzio, "MobiSurf: improving co-located collaboration through integrating mobile devices and interactive surfaces". 2012.

[33] Shaughnessy, J.J. and E.B. Zechmeister, Research methods in psychology, Alfred A. Knopf, 1985.

[34] Vargo, S.L. and R.F. Lusch, "Service-dominant logic: Continuing the evolution", Journal of the Academy of Marketing Science, 36(1), 2008, pp. 1-10. 